\title{
Histogenesis of medullary carcinoma of the thyroid
}

\author{
E. D. WILLIAMS ${ }^{1}$ \\ From the Institute of Pathology, The London Hospital
}

SYNOPSIS Thirty-one dog thyroid tumours and 28 spontaneous rat thyroid tumours were studied histologically and the findings compared with those of a study of 67 cases of medullary carcinoma of the human thyroid.

Five of the dog tumours and 24 of the rat tumours were considered to belong to the same group off tumours as medullary carcinoma, a group characterized by solid sheets or lobules of uniform cells with granular cytoplasm and without papillary or follicular differentiation. In the rat tumours it was shown that the cell of origin was the parafollicular cell and not the thyroid follicle epithelial cell. $\vec{\circ}$

It is suggested that medullary carcinoma is also derived from a parafollicular cell and that this origin would resolve the discrepancy between the relatively good prognosis and the apparentl$\vec{F}$ undifferentiated structure of this tumour. It is also concluded that the whole spectrum of clinical and pathological features of medullary carcinoma makes more sense if it is considered as a parafollicular cell tumour.

Medullary carcinoma of the thyroid is a distinct and clearly defined entity, and the histological features of 67 examples are discussed in the previous paper (Williams, Brown, and Doniach, 1966). The survival of patients with this tumour is often prolonged although paradoxically the vast majority of cases show no evidence of differentiation towards a thyroid epithelial pattern. This paradox is based on the assumption that medullary carcinoma of the thyroid is derived from the thyroid follicular epithelial cells; if this were not so then the absence of papillary or follicular structures would not necessarily imply a lack of differentiation. A second type of thyroid epithelial cell, the 'light' or parafollicular cell, is well described in many animals and the concept that medullary carcinoma of the thyroid is a parafollicular cell tumour seemed plausible. To investigate this hypothesis a comparative study of spontaneous thyroid tumours in dog, rat, and man was undertaken.

\section{DOG}

All cases indexed as thyroid carcinoma in dogs seen at the Royal Veterinary College between 1950 and 1963 were reviewed. Out of 31 tumours from a variety of breeds, 12 were not classified, mainly because of the poor preservation of material sent in by veterinary surgeons from outside the hospital. Of

'Present address: Department of Pathology, Postgraduate Medical School of London, Hammersmith Hospital, London, W.12. the other 19 tumours, two were classified as papillar carcinomas, nine as follicular carcinomas, two as anaplastic carcinomas, while one tumour showed mixture of follicular carcinoma with osteochondro sarcoma. The remaining five tumours were similar and were made up of nests of uniform cells, separateg into groups by a connective tissue stroma which was sometimes dense (Figs. 1 and 2). No amyloid was seen in any tumour. The cells were regular, with granular cytoplasm, mitoses were few, no papillang areas were seen, and neoplastic follicles were absent except in very small numbers in one tumour. The best preserved tumour of this last group containeg large numbers of argyrophil cells with the Bodia technique. Twelve other dog tumours tested were negative.

\section{RAT}

Twenty-eight spontaneous rat tumours were collees ted from various sources, all from rats of 18 monttis of age or over. Two of these were small benigg follicular tumours, and two were mixed papillary and follicular tumours which by the criteria applied to human thyroid neoplasms would have been classit fied as papillary carcinomas. The other 24 were clearly all of the same type, although of wide varying size and showing some variation in pattern and in degree of malignancy. The basic cell of which these tumours were composed was about $14 \mu$ io diameter with a pale, finely granular cytoplasm and 


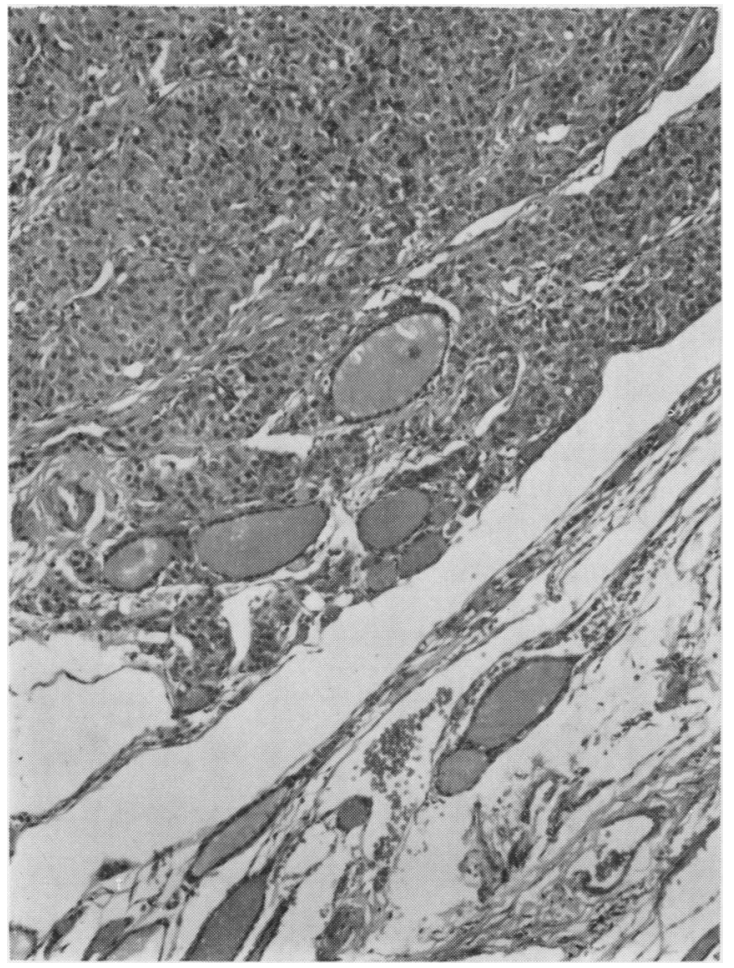

FIG. 1.

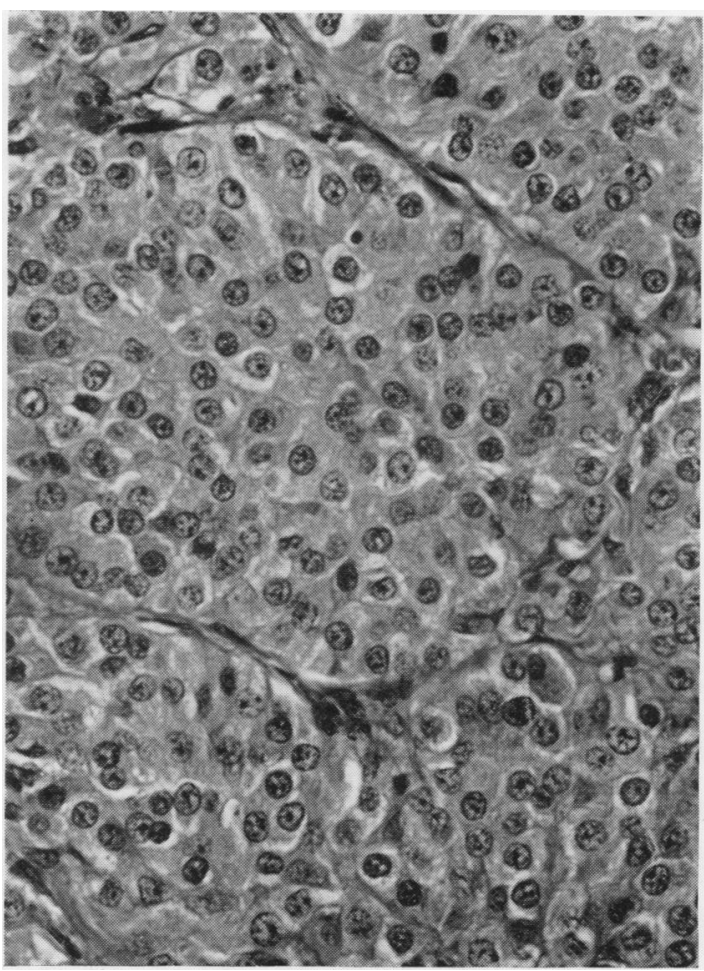

FIG. 2.

FIG. 1. Low-power view of dog thyroid tumour of solid type to show the clearly demarcated margin with a few included thyroid follicles but no neoplastic follicles and no papillary areas (haematoxylin and eosin $\times 100$ ).

FIG. 2. High-power view of the same tumour as in Fig. 1 to show the lobulated arrangement of uniform cells with a pale granular cytoplasm (haematoxylin and eosin $\times 370$ ).

coarsely granular nucleus. The nucleolus was not prominent. The typical tumour was made up of a number of lobules separated by thin collagen strands. Each lobule was composed of sheets of these cells, sometimes with an included non-neoplastic thyroid follicle. These follicles were generally lined by flattened, and sometimes degenerate, thyroid cells. In some tumours there was a greater degree of nuclear pleomorphism and occasional mitoses; in these the lobular pattern was replaced by anastomosing bands of tumour cells, still with occasional included follicles. Cells morphologically similar to the tumour cells are normally found lying singly or in small groups between the follicular epithelium and the basement membrane of the central follicles of the thyroid of rats (Fig. 3). These parafollicular cells are particularly prominent in old rats, and foci of hyperplasia occur (Fig. 4); at times it was difficult to draw a clear dividing line between such hyperplastic areas and true tumours. In the development of the tumours the lobulation was the result of cell proliferation around follicles, separating the follicular epithelium from the basement membrane (Figs. 5 and 6). In the more malignant tumours the basement membrane was transgressed and a lobular pattern transformed into a trabecular one (Fig. 7). Vascular invasion was present in four of the tumours; the presence or absence of distant metastases could not be assessed on the material available. In three tumours the cell type was elongated and spindly, otherwise they were similar in all respects to the remainder. In a few cases some eosinophilic hyaline material was present in the stroma of the tumour, but in no case was unequivocal evidence of amyloid obtained. Neither the parafollicular cell nor the tumour cells were argyrophilic with the Bodian technique.

\section{DISCUSSJON}

The histological features of the human tumours are discussed in the previous paper. It will be seen that in dog, rat, and man there is a group of thyroid tumours which can be clearly separated from the papillary-follicular group of neoplasms, and does 


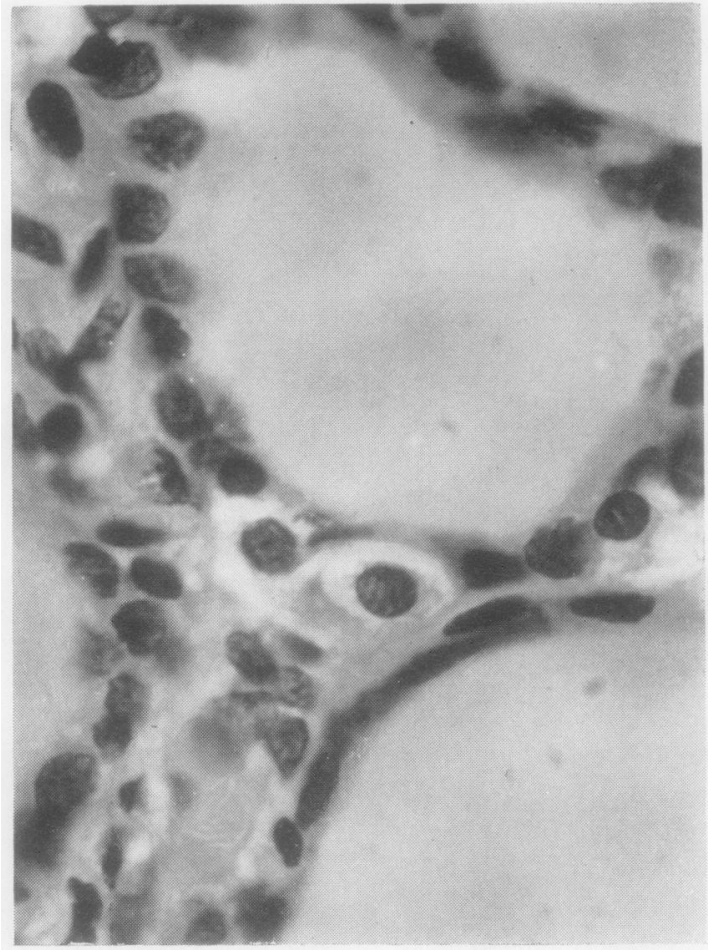

FIG. 3 .

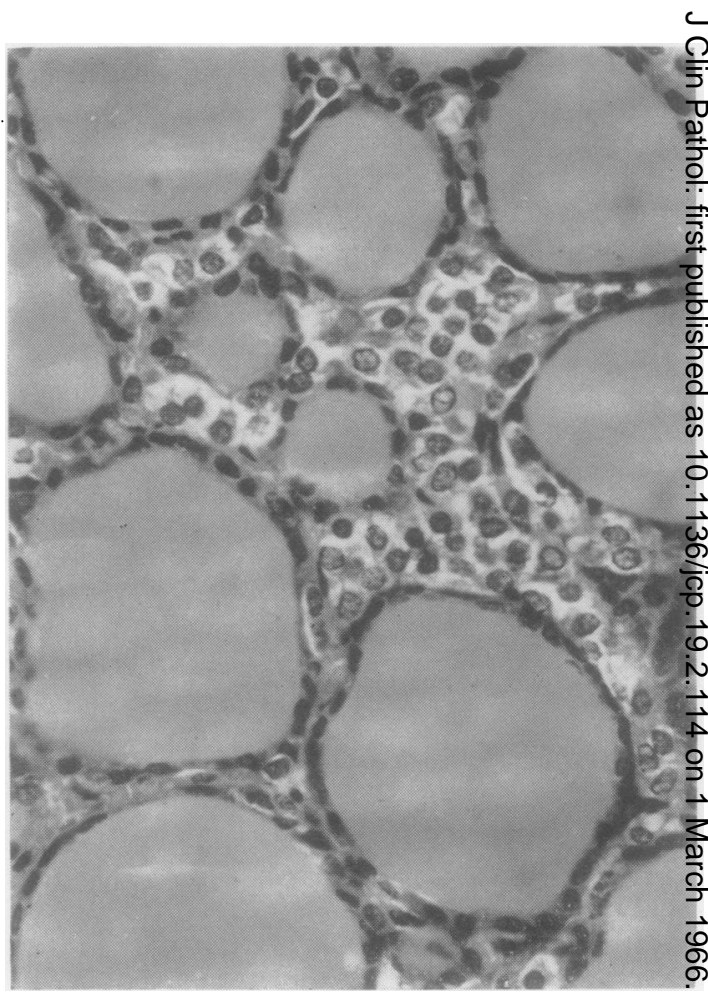

FIG. 4.

FIG. 3. Normal rat thyroid showing two parafollicular cells, identifiable by their position and their pale cytoplasio (formol-saline fixed tissue, haematoxylin and eosin $\times 970$ ).
FIG. 4. Thyroid from a rat aged 20 months to show an area with hyperplastic parafollicular cells (haematoxylin ang $\operatorname{eosin} \times 370$ ).

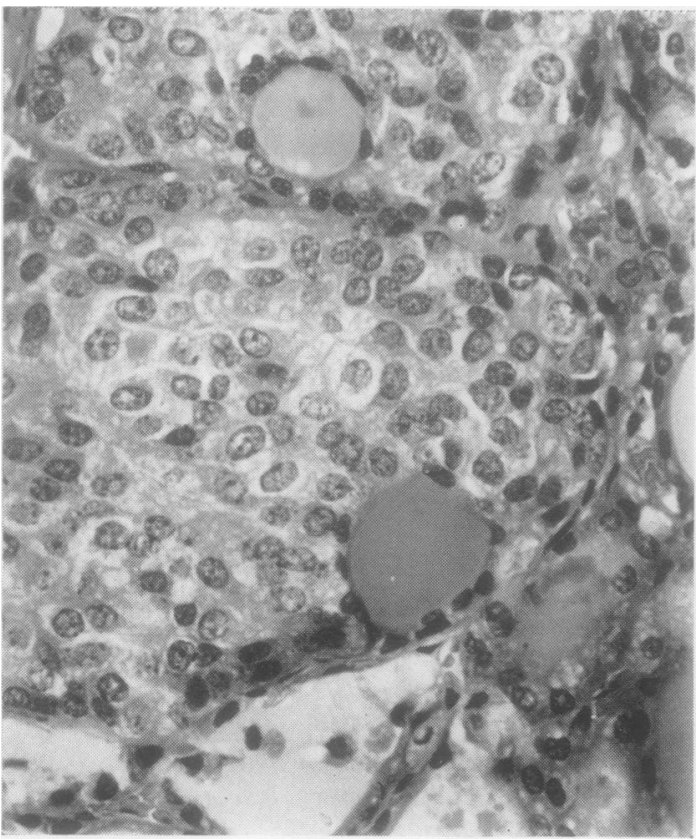

FIG. 5 .

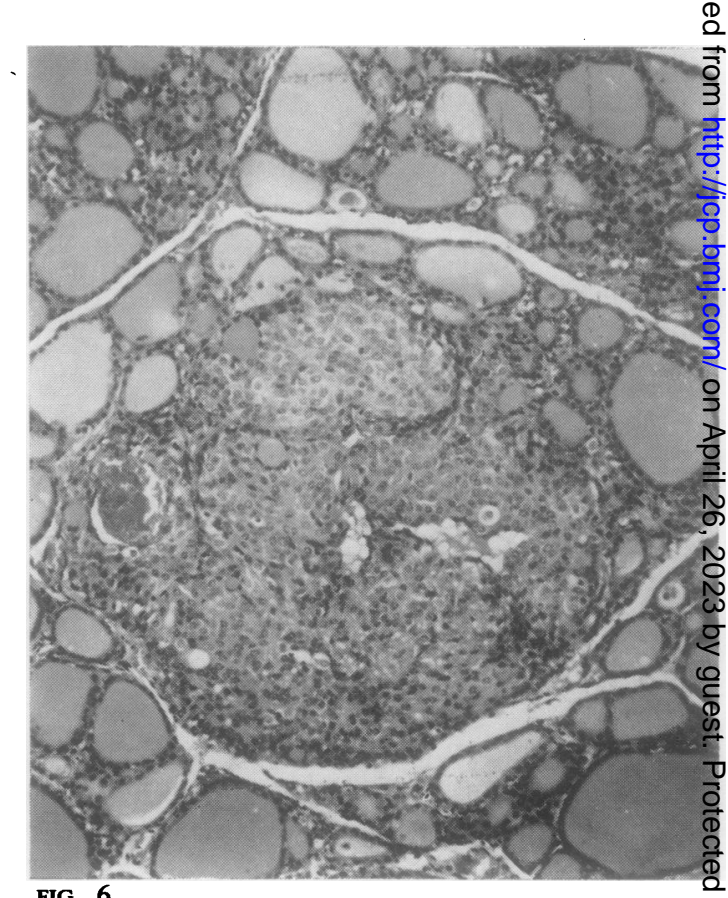

FIG. 6.

FIG. 5. Thyroid from a rat aged 20 months to show the lobular pattern in a spontaneous tumour derived from parar follicular cells. Note the included non-neoplastic thyroid follicles and the absence of any neoplastic follicles or papilla\&, structures (haematoxylin and eosin $\times 370$ ).

FIG. 6. Low-power view of the same tumour as in Fig. 5 (haematoxylin and eosin $\times 100$ ). 


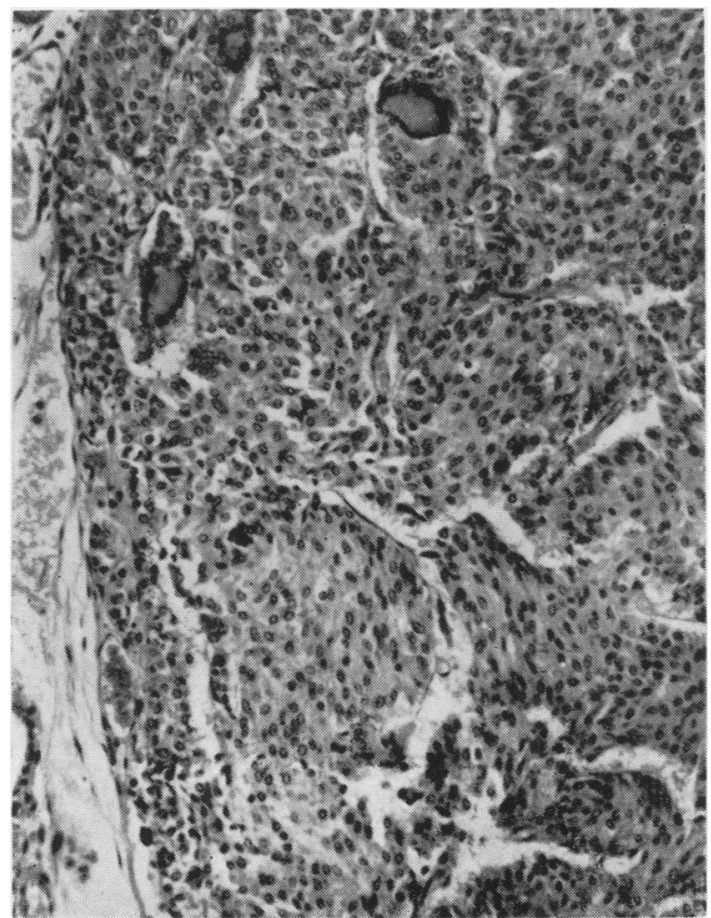

FIG. 7. Another spontaneous rat thyroid tumour showing a trabecular arrangement with a tendency to a spindleshaped cellular pattern (haematoxylin and eosin $\times 150$ ).

not show the gross nuclear variation and frequent mitoses found in the anaplastic carcinomas. In all three mammals the tumours were composed of sheets or groups of regular cells with a granular rather eosinophilic cytoplasm, not forming any papillae, although rarely forming tubular structures. Colloid secretion was not seen. In man the stroma contained amyloid; in rat and dog varying amounts of hyaline collagenous stroma were present but no amyloid was identified. In man and the dog some of these tumours were argyrophil. In the dog these tumours have in the past probably been grouped with the undifferentiated small cell (solid) carcinomas. Clark and Meier (1958) comment that some of this group of tumours bear a resemblance to paragangliomas; it is interesting to note that this was a diagnosis suggested for several human medullary carcinomas before their thyroid origin was apparent. These tumours are relatively uncommon in the dog.

In the rat this type of solid but not anaplastic thyroid tumour is by far the commonest type of spontaneous thyroid neoplasm. These tumours were undoubtedly arising from cells lying between the thyroid follicular epithelium and its basement membrane. Similar cells have been described, under a variety of names, in many mammals. The earliest report was by Baber in 1876, who described these cells in the dog under the term 'parenchymatous' cells. In a later paper he also noted similar cells in various other animals. Nonidez used the term 'parafollicular' cells in his work and in 1932 showed that in the dog these cells were argyrophil, as was one of the dog tumours in this series. Axelrad and Leblond (1955) termed similar cells in the rat 'light cells' and also concluded that the common spontaneous rat thyroid tumour, which they named the $\gamma$ nodule, arose from these cells. These rat tumours have also been described under the term microadenoma by Doniach (1953) and as alveolar carcinomas by Lindsay, Potter, and Chaikoff (1957).

The discussion of these tumours and their cell of origin is made more complex by the variety of suggested names for this second type of thyroid epithelial cell. The term parafollicular cell is preferred here because of the situation of these cells beside the follicular epithelium. The name light cell is descriptive of these cells in the adult rat thyroid after formalin fixation; in formol-mercury-fixed material I have found the cytoplasmic density to be closer to that of the follicular cell.

These studies have shown that in rat, dog, and man there exists a thyroid tumour of a solid but not anaplastic type, known in man as medullary carcinoma. In the rat it is confirmed by the present studies that this tumour is derived from the parafollicular cell, and a similar derivation is proposed for the tumours in dog and man. This hypothesis would explain the discrepancy between the relatively good prognosis of this tumour in man and the lack of any differentiation towards papillary or follicular epithelial structures.

The parafollicular cell has been described in man (Pages, 1956) but its occurrence is not as widely accepted as it is in other mammals. However, the great majority of mammals investigated have been shown to possess parafollicular cells, although in many instances they are found in a part only of the thyroid.

The function of the parafollicular cell is not at present clear. Young and Leblond (1963) considered it a degenerate type of follicular cell from their electron microscope studies. Recently a calciumlowering hormone, calcitonin, has been found in the thyroid (Hirsch, Gauthier, and Munson, 1963) and Foster, MacIntyre, and Pearse (1964) have suggested that it may be derived from a mitochondrion-rich cell. This cell may be equivalent to the parafollicular cell, although the term is apparently used to include the oxyphil follicular cell, also known in the human thyroid as Hürthle or Askanazy cell. Certainly if calcitonin is a second thyroid hormone it may well be 
produced by the second type of thyroid epithelial cell, the parafollicular cell. Falck, Larson, von Mecklenburg, Rosengren, and Svenaeus (1964) have suggested yet another function for the parafollicular cell by their demonstration of 5-hydroxytryptamine in the parafollicular cells of the sheep thyroid. Studies on the human medullary carcinoma and on the parafollicular cell tumours of animals may help to throw light on the functional capacities of the parafollicular cell.

The concept of medullary carcinoma of man as a parafollicular cell tumour not only resolves the discrepancy between its undifferentiated histological appearance and its overall good prognosis, but also helps in the understanding of the considerable variation in the degree of malignancy of this tumour. A small number of tumours in our human series were encapsulated without evidence of metastatic tumour; two of these were originally reported as solid adenomas. In these there is no proof of malignancy. Other cases have shown a very low order of malignancy; one patient is still alive 21 years after resection of a cervical lymph node containing secondary medullary carcinoma; another is alive 17 years after a thyroidectomy with resection of involved cervical nodes. Both these patients still have evidence of residual tumour. At the other extreme, one patient died within a year of first noticing a swelling in his neck. Parafollicular cell tumours might be expected to show a wide spectrum of malignancy, from benign parafollicular adenomas to highly malignant parafollicular carcinomas.

We have previously shown that medullary carcinoma may be associated with multiple mucosal neuromas (Williams and Pollock, 1966); the specific association of medullary carcinoma with phaeochromocytoma has been reviewed elsewhere (Williams, 1965). These findings are easier to understand if medullary carcinoma is considered as arising from a separate cell type rather than being a histological variant of other types of thyroid carcinoma. In the same way the presence of amyloid in the stroma of this type of thyroid tumour but not in papillary or follicular carcinomas is more compatible with a tumour originating from a different cell type than with a variant of follicular carcinoma.
An interesting comparison can be made between medullary carcinoma of the thyroid and islet celt. tumours of the pancreas, in which stromal amyloief deposition has also been described (Porta, Yerry, and Scott, 1962). These tumours may be argyrophil, an show a number of other pathological and clinicat similarities to medullary carcinoma. The thyrois parafollicular cell may well belong to the sampe group as the islet cell and the Kultchitsky cell, and the many varied and interesting features of medullary carcinoma of the thyroid are more easily explained if this is regarded as a parafollicular cell tumour.

It is possible that a benign parafollicular ce tumour may occur in man, although we have ni proof of this. It is also probable that a few tumours which belong to this group may not be associated with amyloid in the stroma. For this reason, as we as its priority, the relatively noncommittal ter? medullary carcinoma is preferred. While it seems likely that these tumours are of parafollicular ce origin, the evidence for this is not yet complete. It therefore intended to continue the use of the term medullary carcinoma, at least until the existence of $\vec{\Phi}$ parafollicular cell in man is conclusively demolpa strated.

I am grateful to Professor E. Cotchin for allowing me study the dog thyroid tumours at the Royal Veterinan College, and to Drs. S. B. de C. Baker and D. B. Cater fof contributing rat tumours.

\section{REFERENCES}

Axelrad, A. A., and Leblond, C. P. (1955). Cancer (Philad.), 8, 339. Baber, E. C. (1876). Proc. roy. Soc., 24, 240.

Clark, S. T., and Meier, H. (1958). Zbl. Vet.-Med., 5, 17.

Doniach, I. (1953). Brit. J. Cancer, 7, 181.

Falck, B., Larson, B., von Mecklenburg, C., Rosengren, E., and Svenaeus, K. (1964). Acta physiol. scand., 62, 491.

Foster, G. V., MacIntyre, I., and Pearse, A. G. E. (1964). Natuge (Lond.), 203, 1029

Hirsch, P. F., Gauthier, G. F., and Munson, P. L. (1963). Endocrinology, 73, 244.

Lindsay, S., Potter, G. D., and Chaikoff, I. L. (1957). Cancer Res., 17 183.

Nonidez, J. F. (1932). Anat. Rec., 53, 339.

Pages, A. (1956). Biol. méd., 45, 414.

Porta, E. A., Yerry, R., and Scott, R. F. (1962). Amer. J. Path., 41, 62 f Williams, E. D. (1965). J. clin. Path., 18, 288.

$\longrightarrow$, Brown, C. L., and Doniach, I. (1966). Ibid., 19, 103.

- and Pollock, D. J. (1966). J. Path. Bact. In press.

Young, B. A., and Leblond, C. P. (1963). Endocrinology, 73, 669. 